\title{
INTERCESSÕES ENTRE LITERATURA E FILOSOFIA SEGUNDO DELEUZE \& GUATTARI
}

Rafael Lovisi Prado*

RESUMO: Levando em conta as segmentações disciplinares dos discursos que giram em torno das artes a partir de meados do século XVIII, diversos impasses ainda ecoam urgente no âmbito das escritas literárias e filosóficas: como criarmos hoje estratégias para que os estatutos das artes e da filosofia sejam respeitados, e que ao fazer artístico e o conceitual sejam concedidos o mesmo brio? Isto é, como ensejar o reconhecimento, por um lado, do aspecto cognitivo da prática artística, e, por outro, do pensamento filosófico direcionado às artes como uma atividade desprendida das amarras metalinguísticas que cindem filosofia e arte por acreditar que o sensível necessita de outra forma de inteligência que o sustente e o comprove? Seguindo tais questionamentos é que o presente texto percorre algumas das proposições de Gilles Deleuze e Félix Guattari em relação às fecundas intercessões entre os campos citados.

PALAVRAS-CHAVE: Intercessões; literatura; filosofia Deleuze; Guattari.
* rafa lovisi@yahoo.com.br

Mestre em Teoria da Literatura e Doutorando em Literatura Comparada e Teoria da Literatura - PÓS-LT/ UFMG.

RÉSUMÉ: Tenant compte de la segmentation disciplinaire des discours tournant autour des arts du milieu du XVIII siècle de nombreux blocages résonnent encore urgent dans le contexte des écrits littéraires et philosophiques: la façon dont nous créons des stratégies pour aujourd'hui afin que les statuts des arts et de la philosophie soient respectés et que la pratique artistique et conceptuelle bénéficient du même panache? Eh bien, comment vouloir la reconnaissance d'une part, l'aspect cognitif de la pratique artistique et, d'autre part, la pensée philosophique dirigée vers les arts comme une activité désintéressée des liens métalinguistiques qui clivent la philosophie et l'art de croire que le sensible a besoin d'une autre forme d'intelligence qui prend en charge et le prouve? Après telles questions, ce est que cet article montre quelquesunes des propositions de Gilles Deleuze et Félix Guattari en relation avec intersections fructueuses entre les domaines mentionnés.

MOTS-CLÉ: Intersections; littérature; philosophie; Deleuze Guattari. 
1. Doravante, sempre que mencionados os termos "arte" ou "artístico" compreendemos, necessariamente, o fazer literário. Esta opção, que a princípio pode sugerir o apagamento das especificidades de cada modalidade, na verdade, como será explicitado a seguir, encontra-se na esteira de certas proposições de Gilles Deleuze e Félix Guattari. Elaborando uma semiótica singular, que corresponde a uma doutrina da gênese sensível do pensamento sob o efeito de uma imagem, os autores almejam intercessões e a quebra da hierarquia entre as diferentes artes. Contudo, obviamente, há traços que pertencem de forma inexorável a cada um dos campos artísticos: “De uma arte a outra, a natureza das imagens varia e e inseparável das técnicas: cores e linhas para a pintura, sons para a música, descrições verbais para a literatura, imagens-movimento para o cinema." (tradução minha). DELEUZE. Deux regimes de fous, p. 194.
É dado comum, nos dias de hoje, que os discursos críticos e teóricos sobre as artes (literatura, pintura, cinema, etc) almejam exercitar a transdisciplinaridade, a partir da qual os limites entre as disciplinas "científicas" possam ser subvertidos em nome da construção de uma horizontalidade mais produtiva. Durante as últimas décadas, talvez desde os últimos anos do século passado, um dos aspectos mais marcantes da pauta acadêmica é a paulatina dissolução das demarcações teóricas entre as disciplinas, desencadeada, sobretudo, pela linhagem pós-estruturalista e pelas vertentes pós-modernas da crítica e da teoria da literatura e de outras artes ${ }^{1}$. Ultrapassado o modelo metodológico estrutura que prevaleceu nos estudos literários a partir dos anos 1960 procedeu-se, entre outros, à retomada da história, à démarche culturalista e à tentativa de se instaurar o que se chamava de interdisciplinaridade. Esta última, inaugurada ainda de forma discreta pela nouvelle vague estruturalista, serviu de referência para os vindouros trabalhos realizados por pesquisadores sobre a estreita relação travada entre o campo artístico e as demais áreas ditas científicas. Diferentemente do que ocorria naquele período áureo da intelligentsia francesa, quando o diálogo interdiscursivo tinha na linguística saussuriana seu articulador preponderante, pode-se perceber na contemporaneidade uma relação que ocorre não por hierarquização ou subordinação, mas mediante a conjugação e o contágio entre as diversas miradas discursivas. Os enunciados, singulares e múltiplos ao mesmo tempo, estreitam-se, se divergem e se assumem despojados de qualquer aspecto que os remetam a uma escala de valor, independente da natureza desta. Dessa maneira, os processos de produção de saber se tornariam mais fecundos e agudos, havendo um número maior de vetores de passagem dos discursos alhures de suas fronteiras, pervertendo assim as palavras da ordem disciplinar, explorando e habitando desertos, limiares, corroendo continuamente o monopólio dos objetos de investigação. Para além dos territórios disciplinares fixados e das especializações verticais (que obviamente também desencadeiam certos efeitos inauditos), encontraríamos a existência reinventada de cada discurso com suas alternativas e novos arranjos. Entretanto, sabemos que este processo, talvez ainda recente, não é passível de simplificações quando, em diversas circunstâncias, é conduzido de forma negligente (como sempre insistiu Deleuze, é preciso cuidado para não afugentar e se experimentar os devires). Neste embate, no qual estão em jogo práxis teóricas distintas, se nos lançamos à aventura da fricção entre os saberes (como o quis Casa Nova) ${ }^{2}$ é preciso estarmos cientes da ameaça de uma indistinção vulgar e da possível rarefação do objeto abordado.

Arrebanhados e guiados pelas diretivas científicas da universidade moderna, os enunciados sobre as artes foram, amiúde, submetidos a crivos e esquadrinhamentos diversos, visto que para se construir sob as referências da
2. Cf. CASA NOVA, Fricções - traço, olho e letra. Belo Horizonte: Ed. UFMG.

\begin{tabular}{|c|c|c|c|c|c|c|}
\hline EM TESE & BELO HORIZONTE & v. 20 & N. 3 & SET.-DEZ. 2014 & PRADO. Intercessões entre literatura e filosofia segundo Deleuze \& Guattari & P. 36-47 \\
\hline
\end{tabular}


modernidade, a ciência rompeu com todos os demais saberes. De certa forma, as ciências fizeram-se herdeiras do método cartesiano, fundamentado na suposição de que a secção em partes nos favoreceria a percepção do todo: a compreensão das fatias como condutora à compreensão absoluta. Como não se apreende o mundo em sua multiplicidade irredutível por completo, tem-se que reparti-lo em alçadas através das disciplinas (as artes, a filosofia, etc.), como se cada um dos platôs do conhecimento somados nos levasse ao Um. Com isso, a modernidade ocupou-se em separar as coisas. $\mathrm{O}$ saber moderno-ocidental ergueu-se assentado em dicotomias, todas impregnadas de aparentes certezas a atravessar o imaginário dos povos, feixe de polaridades que revela um modo bipartido e abissal de se captar o mundo.

Dentre tantas fraturas logradas está aquela que isola o sensível, a subjetividade, partilha orientada à construção de uma razão pura e transcendental. A despeito de qualquer inviabilidade desta tarefa a operação científica moderna enquadrou a filosofia, a literatura e as demais artes mantendo-as a distância. Negação explicita do jogo de montar ideias dos diálogos que traduzem experiências sensíveis do mundo e que liberam a palavra plural, o saber-ciência tomou a babel polifônica dos saberes "menores" como artifício para sua subida aos céus do conhecimento. De outra parte, estabeleceu-se o paradigma no qual o objeto a ser investigado é a realidade externa intocável, portadora da verdade a ser desvelada (alethéia), delineando-se um movimento que busca a verdade contida na realidade tal como ela é - como se tal objeto pudesse existir, positivamente, alijado de qualquer processo de subjetivação. Assim, a presença da subjetividade que se entrelaça declaradamente ao seu objeto (tal como percebemos, por exemplo, nos Esssais de Montaigne) mostra-se ao texto científico como algo intolerável - é preciso limpar as supostas impurezas, ambiguidades, higienizar o texto. A improvisação é confinada às artes, compreendida pela doxa em vigor como um desvio da racionalidade, e as abordagens criativas, por sua vez, são limitadas por uma única diretriz, como se do campo de forças conflitantes que envolvem qualquer problema emergisse apenas um discurso mestre.

No terreno analítico haveria a aspiração a uma determinação em elevado grau, que pudesse contemplar valores como precisão, verificabilidade e irrevogabilidade de conclusões. Já no plano artístico, a indeterminação teria um papel dominante, justamente por banir regras a priori e defender a independência criativa do artista. Mas, é fácil notar que as concepções de teoria (ciência) e arte apresentadas desta maneira, apesar de convincentes à primeira vista, são redutoras, restritas aos olhares positivistas e românticos que embasam o senso comum. Ao confrontarmos tais concepções com os deslocamentos promovidos pelo contemporâneo, é possível 
3. PERNIOLA. Desgostos, novas tendências estéticas, p.123. A escolha por estas três grandes linhas, em consonância com os apontamentos da nota $\mathrm{n}^{\circ} 2$, responde ao interesse por uma perspectiva abrangente na qual a intercessão/cisão entre as artes e os discursos por elas suscitados possa ser apreendida anteriormente aos novos cortes disciplinares assistidos na primeira metade do século $\mathrm{XX}$, quando a teoria da literatura, por exemplo, é instituída de maneira que seu objeto de estudo fosse refratário aos demais construtos artísticos. entrever que o que se entende atualmente por arte abarca aspectos culturais, logísticos e mercadológicos de determinação; e o que se entende por analítico-teórico pressupõe índices de indeterminação - a suspeita sobre os alcances da linguagem ou a inconsistência de certas estruturas e sistemas adotados. Os parâmetros são postos em xeque ao toque das constantes reinvenções discursivas.

Tendo em vista este panorama, dentre as diversas nomenclaturas e possibilidades de se apreender as linhas discursivas que giram em torno das artes a partir da segunda metade do século XVIII, privilegiemos aquela sugerida por Mário Perniola, na qual encontramos "a teoria dos artistas, a estética e o pensamento poetante". ${ }^{3}$ Esta configuração começa a ganhar contornos com a divisão de duas grandes frentes, visto que o pensamento moderno que se direcionou as artes bipartiu-se, a partir de meados do século das Luzes, por um lado, numa perspectiva especulativa, encarnada pela disciplina nomeada estética, e, por outro, no viés constituído pelos críticos e artistas, ponto de vista fundamentado mediante apontamentos empíricos sobre a especificidade de cada manifestação artística. No primeiro lado referido, encontramos então um plano conceitual arraigado na tradição da filosofia ocidental stricto senso. Neste contexto, a sujeição da literatura à filosofia também se faz presente, na medida em que esta supostamente possui o estatuto de uma linguagem universa e transparente que permitiria separar o literal e o metafórico e dizer a verdade sobre as linguagens impuras. Por esta tradição, ao filosófico corresponderia uma universalização sem sobras, a possibilidade de clivar completamente da sua forma discursiva um conteúdo estilizado, enquanto o literário seria uma manobra atrelada à inseparabilidade de forma e conteúdo (com Kierkegaard e Nietzsche esse contraste foi abalado, evidenciando a irrefutável ponte entre o poético e o filosófico, fato este que, entretanto, não anulou a distinção entre dois campos que se fez condição do surgimento moderno da literatura).

Já no segundo, sobressai o tatear ainda incerto de uma teoria em construção, cujo programa almeja formulações amplas sobre a essência de cada obra de arte. Dando rosto a esta contracorrente parafilosófica estão diversos escritores, pintores e músicos oitocentistas realizando obras de caráter teórico que abordam a natureza da arte, em certa medida, de forma apartada do aparato filosófico profissional. Tais produções traziam consigo, latente ou declaradamente, o pressuposto de que a prática artística possibilitaria um enfrentamento mais direto com seu objeto, e com a própria existência, que a especulação vinda da filosofia, isto é, a crença na expressão de um pensamento que para além da arte abarcaria o mundo em sua realidade. Conseguintes a esta visão, com o advento do século XX e ao longo do seu 
decorrer, os distintos segmentos da criação estética passam a ser portadores, via de regra, de alguma teoria autônoma. Desse modo, por meio das propostas dos próprios artistas, surge uma teoria que concebe a arte como sujeito, e não como objeto, de maneira que o filósofo é afastado da reflexão sobre o artístico, pois este reclamava para si as interrogações sobre si mesmo, sobre as condições de sua possibilidade, sua singularidade e interfaces com a realidade. Diante desta independência da coisa estética, ou melhor, da aspiração da arte a pensar filosoficamente a respeito de si mesma e sobre seu exterior, a filosofia apresentou duas posturas contrárias, gesto que oscilava entre o erigir barreiras de proteção ou desmoroná-las, bifurcado entre a desconsideração do intento filosófico das artes e o assentir a literatura e as outras artes como instâncias de acesso à verdade. A primeira destas posições foi tomada pela estética acadêmica do século XX atuante em um campo de proporções discretas, resguardada durante muito tempo de novas experimentações semióticas como o cinema e a fotografia.

Nas antípodas desta atitude, como abertura do pensamento filosófico à dimensão poética, estaria o denominado pensamento poetante, que podemos considerar como a segunda posição da filosofia ao autônomo da arte e o surgimento da terceira linha discursiva dentre as mencionadas. Como procedimento que visa à poetização dos discursos científicos filosóficos, o pensamento poetante (do qual já encontramos alguns indícios nas experimentações dos românticos de Jena), ao contrário da estética ensimesmada com ares de disciplina pura e apartada, toma corpo, sobretudo, nos anos 60 do século passado, por meio do despertar do caráter inventivo da linguagem num franco diálogo com os elementos caros à poética. Sem se constituir como simples reversão, na qual, hierarquicamente, a filosofia estaria submetida à poesia, almeja a uma linguagem em que a divisão entre o pensar e o poetar seja rarefeita em nome de uma incessante interrogação sobre qualquer problema a que se dirija. Marcadores identitários de enunciação, contornos do sujeito discursivo, tempo cronológico, espaço referencial ou quaisquer índices da metafísica da presença são assim barrados em favor de um discurso hesitante (suspensão das verdades peremptórias) e de traços sempre provisórios. Porém, para os detratores desta mirada, o que a princípio seria um avivar das potências poéticas e artísticas em geral, na verdade, mostra-se como operação herege na qual a filosofia é subsumida, ou ainda, uma violação que dissolve "não somente a filosofia, mas também a arte". ${ }^{4}$ Os construtos do pensamento poetante, ligados a uma obscuridade improdutiva e a infindáveis interrogações, não chegariam nem perto do êxito de uma verdadeira obra artística.

Diante dos três discursos sobre as artes aqui discriminados (a teoria dos artistas, a estética e o pensamento poetante) questões primordiais se impõem: levando-se em conta
4. PERNIOLA. Desgostos, novas tendências estéticas, p.126

\begin{tabular}{|c|c|c|c|c|c|c|}
\hline EM TESE & BELO HORIZONTE & v. 20 & N. 3 & SET.-DEZ. 2014 & PRADO. Intercessões entre literatura e filosofia segundo Deleuze \& Guattari & P. 36-47 \\
\hline
\end{tabular}


a aporia ainda em vigor sobre os limites formais entre as linguagens, como criarmos hoje estratégias para que os estatutos das artes e da filosofia sejam respeitados, e que ao fazer artístico e o conceitual fossem concedidos o mesmo brio? Isto é, como ensejar o reconhecimento, por um lado, do aspecto cognitivo da prática artística, e, por outro, num plano coextensivo, do pensamento filosófico (direcionado às artes) como uma atividade desprendida das amarras téticas e demonstrativas comuns às cátedras, da eloquência argumentativa / metalinguística que cindi filosofia e arte por acreditar que o sensível necessita de outra forma de inteligência que o sustente e o comprove?

Neste ponto fulcral, a fim de percorremos certos caminhos investigativos que atravessem os questionamentos apresentados até aqui e possibilitem saídas (mesmo que provisórias) às antinomias entre os planos teóricos e artísticos, é que encontramos a obra dos pensadores Gilles Deleuze e Félix Guattari. É provável que a proliferação de perspectivas flexíveis e abrangentes no âmbito dos discursos críticos-teóricos, que se dão para além da apartheid disciplinar, seja tributária, em grande parte, da teoria da multiplicidade, instaurada, mormente, pelo livro Mille plateaux, de 1980, no qual se constrói a imagem do rizoma que visa desconstruir o modelo arborescente do pensamento ocidental. Dentre as transformações eclodidas na atualidade pela abertura sensível no plano dos discursos desencadeada pela obra mencionada, podemos destacar o esmaecimento do ideal de autonomia absoluta, cujo corolário é a impossibilidade de que o literário, o artístico, seja disposto em situação desprivilegiada. A contaminação entre as esferas proporciona uma cena de fluxo contínuo de transferências e apropriações. Por outro lado, se o lugar de permutas e trânsitos literários, filosóficos e científicos apresenta-se cada vez com mais vigor, fazem-se nele presentes também aqueles que recusam a ruptura com os latifúndios disciplinares e levantam o estandarte da especificidade metodológica como forma de se preservar determinado topos institucional ou epistemológico (reafirmação de traços da modernidade científica já expostos aqui). Nesta esteira, propõe-se, amiúde, a construção de referenciais "consistentes" e bem delimitados teoricamente como forma sensata de monitoramento do discurso assistemático, rizomático e aberto dos estudos literário-artísticos na atualidade. ${ }^{5}$ No entanto, a persistência na defesa de uma particularidade da literatura e das artes no meio de outras manifestações do pensamento deve-se à desconfiança da crítica diante da prática transdisciplinar, lugar teórico que comporta o cruzamento de diversas disciplinas e o apagamento das diferenças relativas ao conceito de autonomia.

Desenvolvendo uma produção intelectual em comum, a quatro mãos, entre os anos de 1969 e 1991, Gilles Deleuze
5. SOUZA. Crítica cult, p.70. 
e Félix Guattari, promoveram uma verdadeira reconfiguração na episteme do século XX, atravessando os campos da psicanálise, política, antropologia, artes, entre outros, numa busca incessante pela prática dos agenciamentos entre os saberes anelada por seu projeto. A dupla de pensadores franceses, o primeiro filósofo de formação, o segundo, psicanalista e ativista político, ao longo de um percurso ora individual (solidão povoada), ora agenciado, buscou driblar a compartimentação dos saberes, sendo movida, até o seu desfecho, pelo ímpeto de percorrer os mil platôs das artes, ciências humanas e, até mesmo, das ciências exatas. Unidos, a princípio, pela avalanche maio de 68, Deleuze e Guattari sempre exerceram seu pensamento em relação a domínios ou objetos heterogêneos, valendo-se não apenas da filosofia de diferentes épocas, mas de uma pluralidade de produções (a pintura de Cézanne e Bacon, o cinema de Resnais e Godard, e, mormente, a literatura de vários escritores).

Em especial para Deleuze, que escreveu paralelamente à elaboração de sua própria filosofia monografias sobre Bergson, Hume, Nietzsche, Spinoza e Kant, a filosofia não está em estado de reflexão externa sobre os outros domínios, mas sim em estado de aliança ativa e interna entre eles. Neste veio, o próprio filósofo distancia-se da imagem clássica do observador purista e reflexivo para ser alçado à condição de criador. Com efeito, o que se pretende é insurgir contra a caracterização da filosofia, e do discurso teórico em geral, como metadiscurso, metalinguagem, em suma, como uma verdade sobre determinado objeto: de fato, o que importa é retirar do filósofo o direito à reflexão sobre. "O filósofo é criador, ele não é reflexivo". ${ }^{6}$ Desta maneira, quando o pensamento deleuze-guattariano coloca a filosofia em relação íntima com saberes de outros territórios, com outros modos de expressão, o intuito não é justificá-los ou legitimá-los, muito menos enquadrá-los, mas realizar conexões ou ressonâncias entre um domínio e outro, a partir da questão primordial que orienta suas investigações: "o que significa pensar?, o que é ter uma ideia?, na literatura, nas ciências, na artes, na filosofia”.?

Ademais, é notório o intrínseco diálogo que o trabalho de Deleuze e Guattari sempre travou com o universo literário. No que tange ao trabalho solo de Deleuze, até 1979, todos os títulos engendrados com a arte são consagrados à literatu$\mathrm{ra}^{8}$. Entretanto, dentre as diversas publicações que priorizam justamente este eixo, raras são as que se detêm nas proposições contidas em sua última obra escrita em conjunto, qual seja, O que é a filosofia? Ora, tendo em vista apenas este título, imediatamente podemos questionar: o que uma investigação filosófica teria a ver com a literatura e demais produções artísticas? Vejamos alguns indícios. Logo nas primeiras páginas deparamo-nos com uma resposta clara de seus autores sobre a indagação que nomeia o livro, a saber, "a filosofia é a arte de formar, de inventar, de fabricar conceitos" ${ }^{9}$. Todavia, o
6. DELEUZE. Conversações, p.152.

7. MACHADO. Deleuze, a arte e a filosofia, p. 12-13.

8. Desde a escrita de $O$ Anti-Édipo (1972) até a feitura de $O$ que é $a$ filosofia? (1991), são constantes os diálogos com escritores como Melville, Lawrence, Fitzgerald, Artaud, Miller, Kleist, entre outros. Além disso, destacam-se as obras dedicadas exclusivamente a autores da literatura, como 0 caso de Proust e os signos (1964), escrita por Deleuze, Kafka - por uma literatura menor (1975), escrita com Guattari, e os ensaios de Crítica e Clínica (1993), em grande parte produzidos por Deleuze tendo como foco a literatura. Contudo, a partir de 1980, período que atravessa o intenso trabalho com Guattari, as artes não discursivas entram em cena. Com a parceria é elaborada uma semiótica capaz de considerar os signos na materialidade de uma expressão irredutível à significação linguageira, às leis da linguística: uma semiótica que se opõe a semiologia estruturalista e à semântica e que avulta como um movimento rumo a não hierarquização, seja entre as próprias modalidades artísticas, seja entre estas e o pensamento conceitual.

9. DELEUZE; GUATTARI. O que éa filosofia?, p.8. 
10. DELEUZE. Conversações, p.170.

11. A simbiose entre as criações do filósofo (conceitos) e as do escritor (afectos e perceptos) possível visto que este último, para Deleuze, "é um vidente, um ouvidor", que vê e ouve nos interstícios, nos desvios da linguagem com o objetivo crítico e clínico de captar forças, tornar sensíveis forças invisíveis $\mathrm{e}$ inaudíveis. Cf. DELEUZE. Crítica e clínica, p.9.

12. Devemos ressaltar que os perceptos não são simplesmente percepções, mas sim conjuntos de sensaçoes e de relaçoes que permanecem vivos para além daqueles que os experimentaram, isto é, são independentes do estado daqueles que por eles foram atravessados; já os afectos não se confundem com os sentimentos, pois se apresentam como devires que excedem os que passam por eles, transformando-se ad infinitum. De ambos digamos que são existências que valem por $\mathrm{si}$ mesmas.

13. DELEUZE. Conversações, p.171.

14. DELEUZE; GUATTARI. $O$ que é a filosofia?, p.197. conceito, invenção "que impede que o pensamento seja uma simples opinião, um conselho, uma discussão, uma tagarelice" ${ }^{10}$ é uma multiplicidade, uma articulação de elementos, de componentes, eles mesmos conceituais, distintos, heterogêneos, mas indivisíveis, reunidos em zonas de indiscernibilidade. Assim, levando-se em conta tal formulação, encontramos o vórtice que faz com que a filosofia, na perspectiva aqu abordada, crie uma aliança irremediável com outras áreas, isto é, se o conceito não existe sozinho é porque uma de suas capacidades é a de engendrar visibilidades, fazer ver as coisas ${ }^{11}$ feito este que não seria possível sem a sua ligação com os perceptos e afectos, seres que habitam a literatura e as outras artes. ${ }^{12}$ Os conceitos são precisamente como sons, cores ou imagens, podendo ainda ser expressos por personagens conceituais. Torna-se claro então que, para Deleuze e Guattari, o conceito comporta dimensões inerentemente estéticas, fabricadas pela palavra e pela sintaxe, mas também por um traço, por uma cor, contorno ou nota musical. Em suma, "o afecto, o percepto e o conceito são três potências inseparáveis, potências que vão da arte à filosofia e vice-versa”. ${ }^{13}$ De acordo com estas elaborações, o objetivo da arte, seja qual for seu suporte, "é arrancar o percepto das percepções do objeto e dos estados de um sujeito percipiente, arrancar o afecto das afecções, como passagem de um estado a outro" ${ }^{14}$. O que se conserva, na obra literária, na pictórica ou sonora, é um bloco de sensações, isto é, um composto de perceptos e afectos.
O que interessa a Deleuze e Guattari, dentro da paisagem de confluências entre os discursos tal como a expomos, são as relações entre as artes, a ciência e a filosofia, mas de modo que não haja nenhum privilégio de uma destas disciplinas em relação à outra. Mas, se cada uma delas é criadora, o que compete à arte é criar agregados sensíveis, já o objeto da ciência é criar funções e o da filosofia criar conceitos. Criar, em todos esses domínios, é ter uma ideia, traçar uma linha que não existia na cartografia cultural. Todos estes domínios podem ser definidos, portanto, por seu poder criador ou, mais precisamente, pela exigência de criação de uma nova forma de se pensar. O pensamento não é um privilégio da filosofia: filósofos, cientistas, artistas são antes de tudo pensadores. É devido ao seu próprio desenvolvimento que os campos reverberam uns nos outros. Por este viés é que se faz necessário considerá-los "como espécies de linhas melódicas estrangeiras umas às outras e que não cessam de interferir entre si”. ${ }^{15}$ Se por um lado, há ressonâncias e interferências entre as vertentes criadoras sem que haja primazia de umas sobre as outras, por outro, há especificidade dos saberes "indisciplinados" no sentido em que cada um responde aos seus próprios problemas.

Ainda de acordo com os autores, para se ter uma ideia, para se fabricar uma obra, é preciso, antes de tudo, de intercessores. Sem eles não há invenção, pois o processo criativo são os

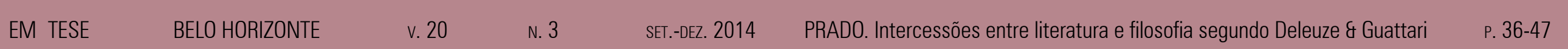


17. Félix Guattari, no início dos anos de 1990, acrescenta densidade rellexiva à questão dimensão política em jogo neste âmbito: “A "A Jogo dos Direitos do Homem ḑa cos Direitos do Homem deveria de to um à po sobre o direito de todos à pesquisa. [...] A interdisciplinaridade, que prefiro chamar de transdisciplinaridade, passa, portanto, acredito, pela reinvenção permanente da décicia, nos divers" estágios do campo social". GUATTAR, "Fundamentos eticopolíticos da interdisciplinaridade", p.19-26. próprios intercessores. Estes, como nos esclarece Deleuze em uma entrevista a Claire Parnet, "podem ser pessoas para um filósofo, artistas ou cientistas; para um cientista, filósofos ou artistas - mas também coisas, plantas, até animais [...]. Fictícios ou reais, animados ou inanimados" ${ }^{16}$, faz-se urgente engendrar seus próprios intercessores, formar uma série, imaginária ou não, desencadeando as potências do falso através das quais seja possível se exprimir. Não obstante, se o exercício da diferença, no sentido que o próprio termo nos revela, proporciona a confluência de objetos de estudo heteróclitos e os bons encontros criativos, ele também distancia o comodismo das semelhanças e a sombra do idêntico. Dadas estas condições, parece mesmo indicado intentarmos diálogos mais transversalistas ${ }^{17}$ entre o artístico e o filosófico que permitam responder a inclusão de ambos no bojo de uma determinada experimentação da escrita e do pensamen to, considerando, concomitantemente, articulações estéticas e conceituais. No horizonte deste caminho é que se torna visível o gradativo declínio do paradigma científico, este que, por sua vez, cede espaço ao paradigma estético, passagem que traz consigo o reconhecimento do caráter ficcional das práticas discursivas e da potência fabulativa das teorias.

A ambição de não mais interpretar, mas de experimentar, de não mais semantizar a obra, mas de se conectar, acoplar a ela: se temos de um lado o plano de composição das artes e, de outro, o plano de imanência da filosofia (segundo a nomenclatura dos autores), podemos fazer deslizar um no outro, "a tal ponto que certas extensões de um sejam ocupadas por entidades do outro". ${ }^{18}$ Desta forma, as elaborações filosóficas podem modificar de maneira decisiva o sentido da literatura do escritor, traçar uma nova imagem do pensamento, instaurar um novo plano de imanência (de conceitos) em sua obra, e, inversamente, o escritor pode povoar a teorização com outras instâncias e entidades, poéticas e romanescas, ou ainda, de personagens conceituais. Por um lado, os planos/ objetos são tão irredutíveis quanto seus elementos: "plano de imanência da filosofia e plano de composição da arte; forma do conceito e força da sensação; conceitos e personagen conceituais, sensações e figuras estéticas" ${ }^{19}$; já por outro, é condição primordial desta démarche fazer com que os pensamentos se entrelacem, se cruzem, mas sem nenhuma síntese apaziguadora ou identificações-decalque, de modo que um fecundo tecido de correspondências seja estabelecido entre os diferentes planos. Cada um dos elementos forjados sobre um plano pode, e deve, recorrer aos demais, em função de revelar uma heterogênese discursiva. Se a literatura é o domínio dos afectos e perceptos, das figuras estéticas, e a filosofia é o campo dos conceitos, criar uma intercessão, ou intercessores, é proporcionar encontros, vasculhar alianças, ecos, ressonâncias, conexões, articulações, agenciamentos e convergências entre os elementos heterogêneos. Segundo esta proposta, as
18. DELEUZE; GUATTARI. O que é a filosofia?, p.81

19. DELEUZE; GUATTARI. O que é a filosofia?, p. 255

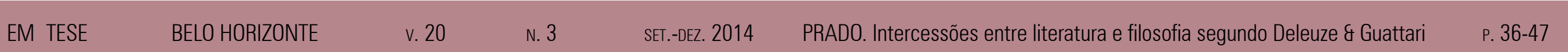


questões literárias reclamarão por uma não-literatura que as suplemente, por um suplemento extra-literário (stricto sensu) que confira a elas novas possibilidades de leitura, assim como o plano filosófico, por sua vez, exigirá também uma não-filosofia. É graças à literatura que a filosofia pode reformar a imagem do pensamento: o que força a pensar é a intrusão violenta e involuntária de um signo, objeto de um encontro que impulsiona o pensamento a criar. Um encontro que se dará não pelos caminhos da dialética (negativo e positivo rumo à plena realização), mas a cada instante de seu desenvolvimento ou devir indecidível, promovendo o trânsito entre os diferentes discursos e objetos teórico-literários de modo que o caráter inventivo de ambos se faça cada vez mais presente no decurso.

Após este resumido itinerário pelas linhas desenhadas por Deleuze e Guattari em torno do problema da segmentação dos saberes/discursos, retomemos a pergunta primeira deste texto: como colocar em jogo num mesmo campo de forças discursivo o sensível e o conceitual, pathos e logos, o artístico e o filosófico/teórico sem demérito ou escalonamento entre as partes? Acredito que as formulações acima apresentadas ensejam o que podemos chamar, a princípio, de uma escrital pensamento sem imagem, isto é, o ensaio de uma forma de se escrever/pensar (pensar e escrever com a literatura e a filosofia, e não sobre) como um procedimento que além de explorar a transversalidade e as intercessões entre as diferentes instâncias criativas, concede às mesmas sua singularidade: uma maquinaria de conceitos que só se torna possível a partir da conexão com os elementos advindos da literatura $e$ das outras artes. A querela sobre a forma artística da teoria talvez encontre aqui um pouco de possível: na heterogênese discursiva deleuze-guattariana, o pensamento teórico/ filosófico alcançaria a dignidade da criação artística. Penso que através desta confluência, não negligenciando todos os meandros atravessados por ela, possamos encontrar um modo de produção de conhecimento no qual as diferenças entre cada discurso, ao invés de constituírem um problema frente à verdade, abririam um espaço por vir no qual a lógica subjetiva (o pensar-sentir) pudesse advir, revelando a cópula entre as artes, a filosofia e as ciências. A tradição que concebe e contrapõe a Teoria (filosófica/científica), enquanto utilização de códigos particulares dotados de regras próprias, as quais podem sofrer mudanças de uma área para outra, aos discursos inventivos, marcados pela ausência de objetividade e descompromisso, seria com isso abalada decisivamente. $\mathrm{O}$ caráter literário/narrativo, neste contexto, seria empregado como meio legítimo de estudo e compreensão dos objetos (estes que deixam de pertencer a uma disciplina da nossa área de eleição), proporcionando um saber paradoxal, precário e inacabado, que é tão mais ligado à realidade quanto mais pratica sua autonomia em relação a ela; que é tão preciso quanto mais descerrado e especulativo. Por sua capacidade de abrigar várias vozes comunicantes simultaneamente,

BELO HORIZONTE

v. 20

N. 3

SET.-DEZ. 2014

PRADO. Intercessões entre literatura e filosofia segundo Deleuze \& Guattari

P. $36-47$ 
apresenta-se assim como um lugar aberto ao pensamento sem imagem. A escrita/pensamento visada por Deleuze Guattari, conjugando diferentes discursos, toma seu objeto, logo de partida e independentemente do estatuto do mesmo, levando-se em conta que este gesto é indissociável da cons tituição do mesmo (nesse sentido, o saber cria o objeto, não apenas busca explicá-lo). Tal operação também aponta para a necessidade ou o desejo de transformar o objeto em algo diferente do que ele é, explicitando que a noção de invenção deve ser válida para todos os campos do conhecimento. A persona teórico-filosófica aproxima-se assim da ficciona por colocar em ação, dramaticamente, seu potencial lúdico com a linguagem, assim como a ficcional, por meio de seus afectos e perceptos, pensa sobre os aspectos caros à teoria A dramatização da escrita/pensamento atuando nos interstícios das palavras de ordem das disciplinas.

\section{REFERÊNCIAS}

CASA NOVA, Vera. Friç̧ões - traço, olho e letra. Belo Horizonte: E. UFMG, 2008.

DELEUZE, Gilles. Crítica e clínica. Tradução Peter Pál Pelbart. São Paulo: Ed.34, 2008.

DELEUZE, Gilles. Conversações, 1972-1990. Tradução Peter Pál Pelbart. São Paulo: Ed.34, 2008.
DELEUZE, Gilles. Francis Bacon: lógica da sensação. Tradução Roberto Machado. Rio de Janeiro: Jorge Zahar Ed., 2007.

DELEUZE, Gilles. Diferença e repetição. Tradução Luiz Orlandi e Roberto Machado. Rio de Janeiro : Graal, 2006a (2ºdição).

DELEUZE, Gilles. Deux regimes de fous. Textes et entretiens 1975-1995. Minuit, 2003.

DELEUZE, Gilles. Foucault. Tradução Claudia Sant'Anna Martins. São Paulo: Brasiliense,1988.

DELEUZE, Gilles; GUATTARI, Félix. Mil platôs: capitalismo e esquizofrenia, vol.3. Tradução Aurélio Guerra Neto, Ana Lúcia de Oliveira, Lúcia Claudia Leão e Suely Rolnik. São Paulo: Editora 34 2012

DELEUZE, Gilles; GUATTARI, Félix. Mil platôs: capitalismo e esquizofrenia, vol.4. Tradução Suely Rolnik. São Paulo: Editora 34,2012

DELEUZE, Gilles: GUATTARI, Félix O que é a filosofia? Tradução Bento Prado Jr. E Alberto Alonso Muñoz. Rio de Janeiro: Ed. 34. 2010.

DELEUZE, Gilles; GUATTARI, Félix. Mil platôs: capitalismo e esquizofrenia, vol.1. Tradução de Aurélio Guerra Neto e Célia Pinto Costa. São Paulo: Ed.34, 2007.

DELEUZE, Gilles; GUATTARI, Félix. Mil platôs - capitalismo e esquizofrenia, vol. 5. Tradução de Peter Pál Pélbart e Janice Caiafa. São Paulo: Ed.34, 1997. 
DELEUZE, Gilles: GUATTARI, Félix. Mil platôs - capitalismo e esquizofrenia, vol. 2. Tradução de Ana Lúcia de Oliveira e Lúcia Cláudia Leão. Rio de Janeiro: Ed.34, 1995.

DELEUZE, Gilles; GUATTARI, Félix. Kafka: por uma literatura menor. Tradução Julio Castanon Guimarães. Rio de Janeiro: 1977

DELEUZE, Gilles; PARNET, Claire. Diálogos. Tradução de José Gabriel Cunha. Lisboa, Ed. Relógio D’Água, 2004.

GUATTARI, Félix. "Fundamentos ético-políticos da

interdisciplinaridade". In Revista Tempo Brasileiro, Rio de Janeiro, n.108, p.19-26, 1992

\section{GUATTARI, Félix. Caosmose: um novo paradigma estético}

Tradução de Ana Lúcia de Oliveira e Lúcia Claudia Leão. Rio de Janeiro: Ed. 34, 1992.

MACHADO, Roberto. Deleuze, a arte e a filosofia. Rio de Janeiro: Jorge Zahar Ed., 2009.

PERNIOLA Mário Desgostos, novas tendências estéticas.

Tradução Davi Pessoa Carneiro. Florianópolis: Editora UFSC 2010

SAUVAGNARGUES, Anne. Deleuze et l'art. Presses Universitaires de France, 2006.

SOUZA, Eneida Maria de. "Literatura Comparada/Indisciplina". Texto apresentado no GT de Literatura Comparada da ANPOLL, na UFF, em julho de 2011.

SOUZA, Eneida Maria de. "Saberes narrativos". Revista Scripta, Belo Horizonte, v. 7, n. 14, p. 56-66, 2004. 